\title{
Synergic effect of oral contraceptives, GSTP1 polymorphisms, and high-risk HPV infection in development of cervical lesions
}

\author{
B.S. Chagas ${ }^{1}$, A.P.A.D. Gurgel ${ }^{2}$, S.S.L. Paiva Júnior ${ }^{3}$, R.C.P. Lima ${ }^{1}$, \\ M.N. Cordeiro', R.R. Moura ${ }^{4,5}$, A.V.C. Coelho ${ }^{4}$, K.C.G. Nascimento ${ }^{1}$, \\ J.C. Silva Neto ${ }^{6}$, S. Crovella ${ }^{4,5,7}$ and A.C. Freitas ${ }^{1}$ \\ ${ }^{1}$ Laboratório de Estudos Moleculares e Terapia Experimental, \\ Departamento de Genética, Universidade Federal de Pernambuco, \\ Recife, PE, Brasil \\ ${ }^{2}$ Departamento de Engenharia e Meio Ambiente, Universidade Federal da Paraíba, \\ Rio Tinto, PB, Brasil \\ ${ }^{3}$ Unidade Acadêmica de Serra Talhada, Universidade Federal Rural de Pernambuco, \\ Serra Talhada, PE, Brasil \\ ${ }^{4}$ Laboratório de Variabilidade e Genética Humana, Departamento de Genética, \\ Universidade Federal de Pernambuco, Recife, PE, Brasil \\ ${ }^{5}$ Instituto de Saúde Materno-Infantil, IRCCS Burlo Garofolo, Trieste, Itália \\ ${ }^{6}$ Laboratório de Pesquisa Molecular e Citológica, Departamento de Histologia, \\ Universidade Federal de Pernambuco, Recife, PE, Brasil \\ ${ }^{7}$ Universidade de Trieste, Trieste, Itália \\ Corresponding author: D.C. Freitas \\ E-mail: acf_ufpe@yahoo.com.br
}

Genet. Mol. Res. 16 (3): gmr16039742

Received May 30, 2017

Accepted August 4, 2017

Published August 17, 2017

DOI http://dx.doi.org/10.4238/gmr16039742

Copyright (C) 2017 The Authors. This is an open-access article distributed under the terms of the Creative Commons Attribution ShareAlike (CC BY-SA) 4.0 License.

ABSTRACT. Human papillomavirus (HPV) infection is considered a risk
factor for cervical cancer. Even if the high-risk HPV (HR-HPV) infection
is necessary, environmental co-factors and genetic susceptibility also play
an important role in cervical cancer development. In this study, a possible

Genetics and Molecular Research 16 (3): gmr16039742 
association of rs1695 GSTP1 polymorphisms, HR-HPV infection, and oral contraceptive use with cancer lesion development in women was investigated. The study population comprised 441 Brazilian women from the Northeast region including $98 \mathrm{HPV}$-infected women with high-grade squamous intraepithelial lesions, 77 HPV-infected women with lowgrade squamous intraepithelial lesions, and 266 HPV-negative women with no lesion, used as a control. Our data did not show a significant association between the GSTP1 polymorphism A/G (rs1695) and any HPV-related cervical abnormalities. However, considering the use of oral contraceptives, the GSTP1 rs1695 polymorphism was associated with higher susceptibility to the development of cervical lesions in HR-HPV-infected women. Our study suggests a synergic effect of oral contraceptive use, GSTP1 polymorphisms, and HR-HPV infection in the development of cervical lesions. Together, these risk factors may induce neoplastic transformation of the cervical squamous epithelium, setting conditions for secondary genetic events leading to cervical cancer.

Key words: Cervical cancer; Contraceptive; Glutathione S-transferase; Human papillomavirus

\section{INTRODUCTION}

Cervical cancer has been recognized as the third most diagnosed malign disease in worldwide women (Jemal et al., 2011). Following World Health Organization (WHO), human papillomavirus (HPV) persistent infection is the central risk factor for developing cervical cancer, and it is estimated that about $98 \%$ of this disease is associated with oncogenic types of HPV (Bosch et al., 2002). It is established that high-risk HPV infection is necessary, but it is not the cervical cancer determinant (de Freitas et al., 2012). Genetic and environmental factors are intricate and act in synergy in the development of cervical cancer (Moore et al., 2012). Cervical cancer development is associated with several genetic and environmental co-factors, including oral contraceptives (Ylitalo et al., 1999; La Vecchia and Boccia, 2014). On the other hand, polymorphisms in different host genes may influence cancer likelihood (Wajid et al., 2007).

Several studies have found that long-term oral contraceptive use is associated with a set of cancers, including cervical, breast, and liver cancers (La Vecchia et al., 2001; Urban et al., 2012). E6 and E7 oncogenes are regulated by transcriptional factor interaction with a viral noncoding sequence, known as a long control region (LCR). Interestingly, according to Weyn et al. (2011), the LCR contains response elements for progesterone and glucocorticoid, and Chen et al. (1996) proposed that HPV-16 expression may be stimulated by estrogens and progesterone through the activation of nuclear receptors. The synthetic estrogens found in oral contraceptive have augmented estrogenic activity compared with endogenous estrogen in some tissues (Kumar et al., 2016).

The glutathione S-transferase (GST) gene family encodes a group of isoenzymes that promotes intracellular detoxification by glutathione conjugation to electrophiles, allowing elimination of potential danger compounds (Hayes et al., 2005). Polymorphisms in GSTcoding sequences may allow different levels of response to environmental factors, as toxins and carcinogens, which would contribute to cancer susceptibility (Josephy, 2010).

Genetics and Molecular Research 16 (3): gmr16039742 
According to sequence homology, GST is distributed into eight classes: Alpha, Mu, Pi, Kappa, Theta, Omega, Sigma, and Zeta (Mannervik et al., 1992). The GSTP1 gene, a member of the GST Pi class, has approximately $3.2 \mathrm{~kb}$ and is found on chromosome 11q13 (Rodríguez et al., 2014). GSTP1 is involved in cell protection through the apoptotic process, and its polymorphic forms do not synthesize essential proteins that bind to enzymes present in the JNK pathway (De Luca et al., 2012). GSTP1 comprises nine exons; the most common polymorphisms are the $\mathrm{A} / \mathrm{G}$ transition at nucleotide 313 (isoleucine/valine substitution codon 105 in exon 5) (rs1695) (Elhoseiny et al., 2014). It was evidenced that the GSTP1 polymorphism A/G (rs1695) is associated with testicular, bladder, and lung cancer (Hengstler et al., 1998).

The relationship between cervical cancer and polymorphisms in GST has been explored in numerous studies, which indicate that cervical cancer risk is increased in women carrying rs1695 polymorphism in the GSTP1 gene (Joseph et al., 2006; Singh et al., 2008). So, we investigated the association of the rs1695 GSTP1 polymorphism with cervical lesions in the presence of environmental co-factors in HPV-infected women from North East Brazil.

\section{MATERIAL AND METHODS}

\section{Study group}

The samples analyzed in this study were acquired by cervical scraping from 441 women that participated in the cervical cancer screening in Clinical Hospital (HC) and Oswaldo Cruz University Hospital (HUOC) in Pernambuco State, Northeastern Brazil. The control group consisted of 266 women with normal cytological results and HPV-negative (healthy control), whereas the case group consisted of 175 women with cervical abnormalities who were divided into LSIL ( $\mathrm{N}=77$ - low-grade squamous intraepithelial lesions) and HSIL $(\mathrm{N}=98$ - highgrade squamous intraepithelial lesions), all HPV-positive. All women (patients and controls) were from the similar geographical area (Northeastern, Brazil). The age of patients with HPVpositive cervical abnormality ranged from 16 to 82 years (average $35.2 \pm 12.2$ ), and the age of the controls ranged from 16 to 65 years (average $35.5 \pm 10.2$ ).

All clinical investigation developed in this study was conducted according to the principles expressed in the Declaration of Helsinki. The objectives of the research were informed to the patients enrolled. Approval of the Ethics Committee was obtained (Research Ethics Committee - Health Sciences Center/Federal University of Pernambuco - CEP/CCS/UFPE No. 491/11) and the consent was signed by all women. A questionnaire about characteristics of women such as sexual behavior and the oral contraceptives used (environmental risk factors) was carried out to investigate the increased risk of cervical neoplasia.

\section{DNA isolation and HPV analysis}

The cervical cells collected with cytobrush were added in $\mathrm{pH} 7.4$ phosphate-buffered saline and maintained at $-80^{\circ} \mathrm{C}$ until the time of DNA extraction. DNeasy Blood and Tissue Kit (Qiagen) was utilized to extract the genomic DNA from cervical cells following the manufacturer's manual. HPV genotyping was performed using the Bioplex technology (BioRad, Hercules, CA, USA) following protocols already reported in the literature (Comar et al., 2012).

Genetics and Molecular Research 16 (3): gmr16039742 


\section{GSTP1 genotyping}

The genotyping of polymorphism in the GSTP1 gene, rs1695 (A/G), was performed with fluorogenic allele-specific probes (TaqMan ${ }^{\circledR}$ Probes, Applied Biosystems) using $50 \mathrm{ng}$ DNA and the ABI7500 Real-Time Polymerase Chain Reaction platform (Applied Biosystems). Allelic discrimination was obtained using the SDS software 2.3 (Applied Biosystems) following the manufacturer's instructions.

\section{Statistical analysis}

The statistical analysis was executed using the open-source R software, the SNPassoc package, and the genetics package (González et al., 2007). Conformity to Hardy-Weinberg equilibrium was obtained by the chi-square test with Yates' continuity correction. The Fisher exact test was utilized for pairwise comparison of alleles and genotypes using contingency tables. The association between the comparison group and risk factors was performed using multinomial logistic regression analysis (likelihood test). For all tests, the level of significance was set at $\mathrm{P}<0.05$.

\section{RESULTS}

\section{HPV analysis}

A total of 441 women were genotyped using the BioPlex platform: 175 (39.7\%) were HPV-positive women and $266(60.3 \%)$ were HPV-negative women. HPV-16 was the most common high-risk HPV type, observed in 37 (21\%) HPV-positive patients. HPV-31 and HPV33 were the other types present in $20(11.3 \%)$ and $6(3.4 \%)$ HPV-infected women. Ninety-five women had co-infections. Table 1 shows details of specific HPV type frequencies.

\section{Genotyping of the GSTP1 polymorphism}

The distribution of allele and genotype frequencies of the GSTP1 rs 1695 polymorphism in HPV-infected patients and healthy controls are displayed in Table 2. All the polymorphism frequencies were in Hardy- Weinberg equilibrium (rs1695 - P = 0.131).

When the GSTP1 A/G (rs1695) polymorphism was examined for the case group, the frequencies of the alleles $\mathrm{A}$ and $\mathrm{G}$ were 0.63 and 0.37 , respectively. In the control group, the $\mathrm{A}$ and $\mathrm{G}$ frequencies were 0.62 and 0.38 , respectively. The genotype frequency in the case group was $37 \% \mathrm{AA}, 63 \% \mathrm{AG} / \mathrm{GG}$. In the control group, the genotype frequencies were $42 \% \mathrm{AA}$, $58 \% \mathrm{AG} / \mathrm{GG}$. The more frequent genotype AA was selected as the reference, and the relative disease association of AG and GG genotype was obtained by the odds ratios (OR) and their 95\%CI (Table 2). The GSTP1 A/G (rs1695) SNP did not show significant differences in allele and genotype frequencies when comparing the control and case groups (Table 2).

A multivariate logistic regression analysis disclosed a significant difference in the genotype frequencies for GSTP1 A/G (rs1695) SNPs in HPV-infected patients when the groups SIL (AA $v s$ AG genotype: $\mathrm{OR}=1.57,95 \% \mathrm{CI}: 1.34-2.38$ and $\mathrm{P}=0.003$ ) and HSIL (AA vs AG genotype: $\mathrm{OR}=1.59,95 \% \mathrm{CI}: 0.96-2.63$ and $\mathrm{P}=0.01$ ) were compared with the control group, all adjusted for oral contraceptive use (Table 3 ). When considering the number of sexual partners, there was no difference in either genotypic or allelic frequency for GSTP1 polymorphisms (data not shown).

Genetics and Molecular Research 16 (3): gmr16039742 


\section{Table 1. HPV types in the case group.}

\begin{tabular}{|c|c|c|}
\hline \multirow[t]{2}{*}{ HPV types } & \multicolumn{2}{|c|}{ Cases } \\
\hline & $\mathrm{N}$ & $\%$ \\
\hline \multicolumn{3}{|l|}{ High risk } \\
\hline HPV-16 & 37 & 21 \\
\hline HPV-18 & 1 & 0.6 \\
\hline HPV-31 & 20 & 11.3 \\
\hline HPV-33 & 6 & 3.4 \\
\hline HPV-35 & 1 & 0.6 \\
\hline HPV-51 & 1 & 0.6 \\
\hline HPV-53 & 3 & 1.7 \\
\hline HPV-56 & 1 & 0.6 \\
\hline HPV-58 & 4 & 2.3 \\
\hline \multicolumn{3}{|l|}{ Low risk } \\
\hline HPV-61 & 1 & 0.6 \\
\hline HPV-66 & 1 & 0.6 \\
\hline HPV-70 & 3 & 1.7 \\
\hline HPV-82 & 1 & 0.6 \\
\hline \multicolumn{3}{|l|}{ Co-infections } \\
\hline HPV-16 + HPV-18 & 1 & 0.6 \\
\hline HPV-16 + HPV-31 & 35 & 20 \\
\hline HPV-16 + HPV-33 & 5 & 2.9 \\
\hline HPV-16 + HPV-58 & 4 & 2.3 \\
\hline HPV-18 + HPV-31 & 5 & 2.9 \\
\hline HPV $-18+$ HPV -32 & 1 & 0.6 \\
\hline HPV-11 + HPV-16 & 1 & 0.6 \\
\hline HPV $-31+$ HPV -33 & 2 & 1.1 \\
\hline HPV-31 + HPV-58 & 4 & 2.3 \\
\hline HPV-16 + HPV-18 + HPV-31 & 4 & 2.3 \\
\hline HPV-16 + HPV-31 + HPV-33 & 6 & 3.4 \\
\hline HPV-16 + HPV-31 + HPV-58 & 8 & 4.5 \\
\hline HPV-16 + HPV-33 + HPV-58 & 1 & 0.6 \\
\hline HPV-31 + HPV-18 + HPV-11 & 1 & 0.6 \\
\hline HPV-31 + HPV-33+ HPV-58 & 3 & 1.7 \\
\hline HPV $-16+$ HPV $-31+$ HPV-33 + HPV -58 & 3 & 1.7 \\
\hline Positive undetermined & 11 & 6.3 \\
\hline Total & 175 & 100 \\
\hline
\end{tabular}

Table 2. GSTP1 (rs1695) polymorphisms in patients with HPV and LSIL and HSIL cervical lesions and healthy controls.

\begin{tabular}{l|c|c|c|c|c|c|c}
\hline \multirow{2}{*}{ rs1695 } & \multicolumn{3}{|c|}{ Cases } & Control & \multicolumn{3}{c}{ P value; OR (95\%CI) } \\
\cline { 2 - 8 } & Total $(\mathrm{N}=175)$ & $\begin{array}{c}\text { HPV/LSIL } \\
(\mathrm{N}=77)\end{array}$ & $\begin{array}{c}\text { HPV/HSIL } \\
(\mathrm{N}=98)\end{array}$ & $\begin{array}{c}\text { Normal cytology } \\
(\mathrm{N}=266)\end{array}$ & Total $v s$ control & HPV/LSIL $v s$ control & HPV/HSIL $v s$ control \\
\hline Alelles & & & & & & & \\
\hline A & $222(0.63)$ & $98(0.64)$ & $124(0.63)$ & $328(0.62)$ & Reference & Reference & Reference \\
\hline G & $128(0.37)$ & $56(0.36)$ & $72(0.37)$ & $204(0.38)$ & $0.59 ; 1.07$ & $0.65 ; 1.08$ & $0.69 ; 1.07$ \\
& & & & & & & $(0.81-1.42)$ \\
\hline Genotypes & & & & & & & \\
\hline AA & $65(0.37)$ & $29(0.38)$ & $36(0.37)$ & $113(0.42)$ & Reference & Reference & Reference \\
\hline AG/GG & $110(0.63)$ & $48(0.62)$ & $62(0.63)$ & $153(0.58)$ & $0.26 ; 0.80$ & $0.45 ; 0.81$ & $0.32 ; 0.78$ \\
& & & & $0.54-1.18)$ & $(0.48-1.37)$ & $(0.48-1.26)$ \\
\hline
\end{tabular}

$\mathrm{P}<0.05$ - statistically significant. ${ }^{\mathrm{a}} \mathrm{HPV} / \mathrm{LSIL}: \mathrm{HPV}+$ low-grade squamous intraepithelial lesions. ${ }^{\mathrm{b}} \mathrm{HPV} / \mathrm{HSIL}$ $\mathrm{HPV}+$ high-grade squamous intraepithelial lesions.

Table 3. GSTP1 (rs1695) polymorphisms in patients with HPV and cervical lesions of low grade (LSIL) and high grade (HSIL) and healthy controls with contraceptive as cofactor.

\begin{tabular}{l|c|c|c|c|c|c|c}
\hline \multirow{2}{*}{ Genotypes } & \multicolumn{3}{|c|}{ Cases } & Control & \multicolumn{3}{c}{ P value; OR (95\%CI) } \\
\cline { 2 - 8 } & Total & HPV/LSIL & HPV/HSIL & Normal cytology & Total $v$ control & HPV/LSIL $v$ control & HPV/HSIL $v s$ control \\
\hline AA & $65(0.37)$ & $29(0.38)$ & $36(0.37)$ & $113(0.42)$ & Reference & Reference & Reference \\
\hline AG & $92(0.53)$ & $40(0.52)$ & $52(0.53)$ & $102(0.38)$ & $0.003 ; 1.57$ & $0.05 ; 1.53$ & $0.01 ; 1.59$ \\
& & & & & $(1.34-2.38)$ & $(0.88-2.67)$ & $(0.96-2.63)$ \\
\hline GG & $18(0.10)$ & $8(0.10)$ & $10(0.10)$ & $51(0.19)$ & $0.61 ; 0.83$ & $0.61 ; 0.80$ & $0.61 ; 0.87$ \\
& & & & & $(0.33-1.14)$ & $(0.26-1.44)$ & $(0.28-1.32)$ \\
\hline
\end{tabular}

$\mathrm{P}$ value adjusted with contraceptive. Codominant model. $\mathrm{P}<0.05$ - statistically significant. ${ }^{\mathrm{a} H P V / L S I L: ~ H P V ~+~}$ low-grade squamous intraepithelial lesions. ${ }^{b} \mathrm{HPV} / \mathrm{HSIL}$ : HPV + high-grade squamous intraepithelial lesions.

Genetics and Molecular Research 16 (3): gmr16039742 


\section{DISCUSSION}

The case-control study was executed to investigate the association among genetic variants of the GSTP1 gene and susceptibility to HPV infection and development of cervical lesions in a population from Pernambuco, Brazil. We compared case subjects (LSIL and HSIL - women positive for HPV) with control subjects (women without HPV infection and lesions).

Studies performed in Brazil have shown that HPV-16 is the most common (Baldez da Silva et al., 2009; Fernandes et al., 2011). Our findings showed that in Northeastern Brazil the HPV-16 was the most prevalent genotype followed by HPV-31 and HPV-33. The results of the frequency of HPV subtypes found in this study did not show any difference concerning other studies conducted in Northeastern Brazil (Baldez da Silva et al., 2009; Fernandes et al., 2011; Chagas et al., 2015).

GST enzymes can inactivate drugs, by conjugating a glutathione radical to electrophiles, and, so, allowing toxin and carcinogen elimination from the organism (Strange et al., 2001; Townsend and Tew, 2003). GST-mediated intracellular detoxification efficiency depends on agent chemical structure, individual genetic background, gender, age, and diet (Sheweita, 2000). One of the most studied GST, known as GSTP1, acts as stress agent-related signaling pathway regulator, further signaling pathways in response to hypoxia and growth factors (Kou et al., 2013). In MAPK kinase pathway, GSTP1 suppresses MEKK1 activity (Zhao et al., 2006). Genetic variations in GSTP1 sequences may be relevant in cancer susceptibility because it may promote differential metabolism of carcinogen and anti-carcinogen compounds (Nakajima and Aoyama, 2000).

The role of genetic susceptibility to HPV infections and cervical cancer development is complex and the aim of several studies. Our case-control study investigated whether the GSTP1 polymorphism A/G (rs1695) would influence the risk of HPV-associated cervical lesions under homozygous or heterozygous condition. Our data did not show a significant association between allele or genotype frequencies of GSTP1 polymorphisms $\mathrm{A} / \mathrm{G}$ and $\mathrm{C} / \mathrm{T}$ and any HPV-related cervical abnormalities. Our results were coherent with previous data, where the presence of the GSTP1 (Ile105Val) polymorphism produced no difference in cervical cancer risk observed between the patient and control groups (Kiran et al., 2010).

However, associations may be found between genetic background and cancer susceptibility when environmental co-factors are considered. More than the metabolism of environmental carcinogens, GST gene products are also involved in estrogen metabolism (Henningson et al., 2010). So, variations in GST genes may be relevant in a condition of long-term exposure to synthetic estrogens, such as those observed in oral contraceptive users. For example, the frequent use of oral contraceptives is associated with increased risk of breast cancer development (Jernström et al., 2005), although not all studies confirmed such findings (Hannaford et al., 2007). It is possible that polymorphisms present in genes involved in hormone metabolism or mediated by effects of estrogens cause such controversial results. In HPV-related cancers, there is no study reporting a plausible association between oral contraceptive-related cancer risk and GST polymorphisms.

Our data suggested an association between GST polymorphisms and increased cervical lesion risk in oral contraceptive users. This finding may be relevant when it is considered the possibility that synthetic steroids from oral contraceptives enhance HPV E6/E7 expression. HPV-18 LCR carries a specific sequence in its promoter-proximal region, which confers dexamethasone and progesterone inducibility (Butz and Hoppe-Seyler, 1993; Efird

Genetics and Molecular Research 16 (3): gmr16039742 
et al., 2011), corresponding to a glucocorticoid-responsive element (GRE). Later, mutational analysis has demonstrated that inactivation of this GRE within the promoter-proximal portion of the HPV-18 LCR abolished the dexamethasone response of the E6/E7 promoter (Butz and Hoppe-Seyler, 1993). Some additional progesterone/GREs have also been found within HPV11, HPV-16, and HPV-31 LCR (Chen et al., 1996; Bromberg-White and Meyers, 2002). So, if a significant variation in estrogen/progesterone metabolism might be a consequence of GST polymorphism- and estrogen-upregulated HPV E6/E7 oncogene expression, cancer risk would also be altered in HPV-positive patients who use oral contraceptive methods and present some of the GST described polymorphisms. To the best of our knowledge, this is the first study that has investigated this type of association between the GSTP1 gene polymorphism and use of oral contraceptives, in the presence of HPV-related cervical abnormalities.

Chronic estrogen exposure is a key factor for the development of HPV-related cervical cancer. Our study suggests a synergic effect of estrogens, GST polymorphisms, and high-risk HPV infection in the development of cervical lesions. Taken together, these risk factors may induce neoplastic transformation of the cervical squamous epithelium, setting conditions for secondary genetic events leading to cervical cancer.

\section{ACKNOWLEDGMENTS}

The authors thank PROPESQ/UFPE, the Program for Technological Development in Tools for Health - PDTIS FIOCRUZ and the Technology Platform of Sequencing of Laboratory of Genomics and Gene Expression - LABCEN/CCB/UFPE for the use of its facilities. The authors also thank the physicians and nurses of the Oswaldo Cruz University Hospital (HUOC) and Clinical Hospital (HC) in Pernambuco State, for their significant contributions, and all participants who provided samples for this study. Research supported by Fundação de Amparo à Ciência e Tecnologia do Estado de Pernambuco (FACEPE), Programa de Núcleos Emergentes (PRONEM - APQ-0562-2.02/14), and RC06/11 from IRCCS Burlo Garofolo (Trieste, Italy).

\section{REFERENCES}

Baldez da Silva MFPT, Chagas BS, Guimarães V, Katz LM, et al. (2009). HPV31 and HPV33 incidence in cervical samples from women in Recife, Brazil. Genet. Mol. Res. 8: 1437-1443. https://doi.org/10.4238/vol8-4gmr677

Bosch FX, Lorincz A, Muñoz N, Meijer CJLM, et al. (2002). The causal relation between human papillomavirus and cervical cancer. J. Clin. Pathol. 55: 244-265. https://doi.org/10.1136/jcp.55.4.244

Bromberg-White JL and Meyers C (2002). The upstream regulatory region of human papillomavirus type 31 is insensitive to glucocorticoid induction. J. Virol. 76: 9702-9715. https://doi.org/10.1128/JVI.76.19.9702-9715.2002

Butz K and Hoppe-Seyler F (1993). Transcriptional control of human papillomavirus (HPV) oncogene expression: composition of the HPV type 18 upstream regulatory region. J. Virol. 67: 6476-6486.

Chagas BS, Comar M, Gurgel APAD, Paiva S, et al. (2015). Association study between cervical lesions and single or multiple vaccine-target and non-vaccine target Human papillomavirus (HPV) types in women from Northeastern Brazil. PLoS One 10: e0132570. https://doi.org/10.1371/journal.pone.0132570

Chen YH, Huang LH and Chen TM (1996). Differential effects of progestins and estrogens on long control regions of human papillomavirus types 16 and 18. Biochem. Biophys. Res. Commun. 224: 651-659. https://doi.org/10.1006/ bbrc. 1996.1080

Comar M, Iannacone MR, Casalicchio G, McKay-Chopin S, et al. (2012). Comparison of hybrid capture II, linear array, and a bead-based multiplex genotyping assay for detection of human papillomavirus in women with negative pap test results and atypical squamous cells of undetermined significance. J. Clin. Microbiol. 50: 4041-4046. https://doi. org/10.1128/JCM.02105-12

Genetics and Molecular Research 16 (3): gmr16039742 
De Luca A, Federici L, De Canio M, Stella L, et al. (2012). New insights into the mechanism of JNK1 inhibition by glutathione transferase P1-1. Biochemistry 51: 7304-7312. https://doi.org/10.1021/bi300559m

Efird JT, Toland AE, Lea CS and Phillips CJ (2011). The combined influence of oral contraceptives and human papillomavirus virus on cutaneous squamous cell carcinoma. Clin. Med. Insights Oncol. 5: 55-75. https://doi. org/10.4137/CMO.S6905

Elhoseiny S, El-Wakil M, Fawzy M and Rahman AA (2014). GSTP1 (Ile105Val) Gene Polymorphism: Risk and Treatment Response in Chronic Myeloid Leukemia. J. Cancer Ther. 5: 1. https://doi.org/10.4236/jct.2014.51001

Fernandes JV, Meissner RdeV, Carvalho MG, Fernandes TA, et al. (2011). Human papillomavirus prevalence in women with normal cytology and with cervical cancer in Natal, Brazil. Mol. Med. Rep. 4: 1321-1326.

de Freitas AC, Gurgel APAD, Chagas BS, Coimbra EC, et al. (2012). Susceptibility to cervical cancer: an overview. Gynecol. Oncol. 126: 304-311. https://doi.org/10.1016/j.ygyno.2012.03.047

González JR, Armengol L, Guinó E, Sol X, et al. (2007). SNPassoc: SNPs-based whole genome association studies. R package version 1.9-2. http://CRAN.R-project.org/package=SNPassoc.

Hannaford PC, Selvaraj S, Elliott AM, Angus V, et al. (2007). Cancer risk among users of oral contraceptives: cohort data from the Royal College of General Practitioner's oral contraception study. BMJ 335: 651. https://doi.org/10.1136/ bmj.39289.649410.55

Hayes JD, Flanagan JU, Jowsey IR, Hayes J, et al. (2005). Glutathione transferases. Annu. Rev. Pharmacol. Toxicol. 45: 51-88. https://doi.org/10.1146/annurev.pharmtox.45.120403.095857

Hengstler JG, Arand M, Herrero ME and Oesch F (1998). Polymorphisms of N-acetyltransferases, glutathione S-transferases, microsomal epoxide hydrolase and sulfotransferases: influence on cancer susceptibility. Recent Results Cancer Res. 154: 47-85. https://doi.org/10.1007/978-3-642-46870-4 4

Henningson MC, Hietala M, Bågeman E, Olsson H, et al. (2010). Interactions between oral contraceptive status and GSTM1 and GSTT1 deletions on insulin-like growth factor-1 (IGF-1) plasma levels in young healthy women. Growth Horm. IGF Res. 20: 432-437. https://doi.org/10.1016/j.ghir.2010.10.003

Jemal A, Bray F, Center MM, Ferlay J, et al. (2011). Global cancer statistics. CA Cancer J. Clin. 61: 69-90. https://doi. org/10.3322/caac. 20107

Jernström H, Loman N, Johannsson OT, Borg A, et al. (2005). Impact of teenage oral contraceptive use in a populationbased series of early-onset breast cancer cases who have undergone BRCA mutation testing. Eur. J. Cancer 41: 23122320. https://doi.org/10.1016/j.ejca.2005.03.035

Joseph T, Chacko P, Wesley R, Jayaprakash PG, et al. (2006). Germline genetic polymorphisms of CYP1A1, GSTM1 and GSTT1 genes in Indian cervical cancer: associations with tumor progression, age and human papillomavirus infection. Gynecol. Oncol. 101: 411-417. https://doi.org/10.1016/j.ygyno.2005.10.033

Josephy PD (2010). Genetic variations in human glutathione transferase enzymes: significance for pharmacology and toxicology. Hum. Genomics Proteomics 2010: 876940. https://doi.org/10.4061/2010/876940

Kiran B, Karkucak M, Ozan H, Yakut T, et al. (2010). GST (GSTM1, GSTT1, and GSTP1) polymorphisms in the genetic susceptibility of Turkish patients to cervical cancer. J. Gynecol. Oncol. 21: 169-173. https://doi.org/10.3802/ igo.2010.21.3.169

Kou X, Chen N, Feng Z, Luo L, et al. (2013). GSTP1 negatively regulates Stat3 activation in epidermal growth factor signaling. Oncol. Lett. 5: 1053-1057.

Kumar MM, Davuluri S, Poojar S, Mukherjee G, et al. (2016). Role of estrogen receptor alpha in human cervical cancerassociated fibroblasts: a transcriptomic study. Tumour Biol. 37: 4409-4420. https://doi.org/10.1007/s13277-015$\underline{4257-6}$

La Vecchia C and Boccia S (2014). Oral contraceptives, human papillomavirus and cervical cancer. Eur. J. Cancer Prev. 23: 110-112. https://doi.org/10.1097/CEJ.0000000000000000

La Vecchia C, Altieri A, Franceschi S and Tavani A (2001). Oral contraceptives and cancer: an update. Drug Saf. 24: 741754. https://doi.org/10.2165/00002018-200124100-00003

Mannervik B, Awasthi YC, Board PG, Hayes JD, et al. (1992). Nomenclature for human glutathione transferases. Biochem. J. 282: 305-306. https://doi.org/10.1042/bj2820305

Moore EE, Wark JD, Hopper JL, Erbas B, et al.; CeCaGeEn Study Group (2012). The roles of genetic and environmental factors on risk of cervical cancer: a review of classical twin studies. Twin Res. Hum. Genet. 15: 79-86. https://doi. org/10.1375/twin. 15.1 .79

Nakajima T and Aoyama T (2000). Polymorphism of drug-metabolizing enzymes in relation to individual susceptibility to industrial chemicals. Ind. Health 38: 143-152. https://doi.org/10.2486/indhealth.38.143

Rodríguez M, Mejia F, Lecourtois M, Domínguez V, et al. (2014). Influence of GSTT1, GSTM1 and GSTP1 Polymorphisms on the Development of Breast Cancer. J. Cancer Ther. 5: 552-559. https://doi.org/10.4236/jct.2014.56063

Genetics and Molecular Research 16 (3): gmr16039742 
Sheweita SA (2000). Drug-metabolizing enzymes: mechanisms and functions. Curr. Drug Metab. 1: 107-132. https://doi. org $/ 10.2174 / 1389200003339117$

Singh H, Sachan R, Devi S, Pandey SN, et al. (2008). Association of GSTM1, GSTT1, and GSTM3 gene polymorphisms and susceptibility to cervical cancer in a North Indian population. Am. J. Obstet. Gynecol. 198: 303.e1-303.e6. https://doi.org/10.1016/j.ajog.2007.09.046

Strange RC, Spiteri MA, Ramachandran S and Fryer AA (2001). Glutathione-S-transferase family of enzymes. Mutat. Res. 482: 21-26. https://doi.org/10.1016/S0027-5107(01)00206-8

Townsend D and Tew K (2003). Cancer drugs, genetic variation and the glutathione-S-transferase gene family. Am. J. Pharmacogenomics 3: 157-172. https://doi.org/10.2165/00129785-200303030-00002

Urban M, Banks E, Egger S, Canfell K, et al. (2012). Injectable and oral contraceptive use and cancers of the breast, cervix, ovary, and endometrium in black South African women: case-control study. PLoS Med. 9: e1001182. https:// doi.org/10.1371/journal.pmed.1001182

Wajid S, Naqvi SH, Juneja A, Bharadwaj M, et al. (2007). Allelic variations in CYP2D6 gene and susceptibility to cervical cancer. Drug Metab. Lett. 1: 276-280. https://doi.org/10.2174/187231207783221367

Weyn C, Vanderwinden JM, Rasschaert J, Englert Y, et al. (2011). Regulation of human papillomavirus type 16 early gene expression in trophoblastic and cervical cells. Virology 412: 146-155. https://doi.org/10.1016/j.virol.2010.12.056

Ylitalo N, Sørensen P, Josefsson A, Frisch M, et al. (1999). Smoking and oral contraceptives as risk factors for cervical carcinoma in situ. Int. J. Cancer 81: 357-365. https://doi.org/10.1002/(SICI)1097-0215(19990505)81:3<357::AIDIJC8 $>3.0 . \mathrm{CO} ; 2-1$

Zhao X, Fan Y, Shen J, Wu Y, et al. (2006). Human glutathione S-transferase P1 suppresses MEKK1-mediated apoptosis by regulating MEKK1 kinase activity in HEK293 cells. Mol. Cells 21: 395-400.

Genetics and Molecular Research 16 (3): gmr16039742 